\title{
Osteoprotective effects of osthole in a mouse model of 5/6 nephrectomy through inhibiting osteoclast formation
}

\author{
XIAOFENG LI ${ }^{1,2^{*}}$, CHUNCHUN XUE $^{1,2^{*}}$, LIBO WANG $^{1,2}$, DEZHI TANG $^{1,2}$, JIAN HUANG ${ }^{3}$, YONGJIAN ZHAO ${ }^{1,2}$, \\ YAN CHEN $^{1,2}$, DONGFENG ZHAO ${ }^{1,2}$, QI SHI ${ }^{1,2}$, YONGJUN WANG ${ }^{1,2}$ and BING SHU ${ }^{1,2}$ \\ ${ }^{1}$ Longhua Hospital; ${ }^{2}$ Spine Research Institute, Shanghai University of Traditional Chinese Medicine, \\ Shanghai 200032, P.R. China; ${ }^{3}$ Department of Biochemistry, Rush University Medical Center, Chicago, IL 60607, USA
}

Received August 19, 2015; Accepted August 11, 2016

DOI: $10.3892 / \mathrm{mmr} .2016 .5687$

\begin{abstract}
The present study aimed to investigate the effects of osthole on osteoclast formation and bone loss in a mouse model of 5/6 nephrectomy. The mice in control and osthole groups were treated 1 month following 5/6 nephrectomy with either a placebo or osthole, respectively. At 2 months post-nephrectomy, the L4 vertebrae were harvested. The bone mineral density (BMD) of cancellous bone was measured using micro-CT and tartrate-resistant acid phosphatase (TRAP) staining was performed to evaluate osteoclast formation. Immunohistochemistry staining and reverse transcription-quantitative polymerase chain reaction were performed to detect the expression of nuclear factor of activated T-cells, cytoplasmic-1 (NFATc-1), c-Fos, cathepsin K, Trap, matrix metalloproteinase $9(\mathrm{Mmp} 9)$, osteoprotegerin $(\mathrm{Opg})$ and receptor activator for nuclear factor- $\kappa \mathrm{B}$ ligand (Rankl). Bone marrow cells were cultured with osthole, and osteoclast formation was shown by TRAP staining. Primary calvaria osteoblasts were cultured with osthole, and expression levels of Opg and Rankl were detected. Compared with the sham group, the BMD of mice in model group was significantly reduced. The numbers of osteoclasts and the expression levels of NFATc-1, c-Fos, cathepsin K and Mmp9 were significantly increased. Compared with the control group, the mice in the osthole group exhibited increased BMD of the L4 vertebrae, a reduction in osteoclast numbers and decreased expression levels of NFATc-1, c-Fos, cathepsin K and Mmp9. In vitro experiments also showed that osteoclast formation was decreased following treatment with osthole. Osteoprotegerin $(\mathrm{Opg}) /$ receptor activator for nuclear factor- $\mathrm{B}$ ligand (Rankl)
\end{abstract}

Correspondence to: Dr Yongjun Wang or Dr Bing Shu, Longhua Hospital, Shanghai University of Traditional Chinese Medicine, 725 South Wanping Road, Shanghai 200032, P.R. China

E-mail: yjwang8888@126.com

E-mail: shubing523@hotmail.com

*Contributed equally

Key words: osthole, osteoclast, 5/6 nephrectomy, osteoprotegerin, bone loss, receptor activator for nuclear factor- $\kappa \mathrm{B}$ ligand was upregulated by osthole treatment in the L4 vertebrae and in primary cultures of calvarial osteoblasts. Osthole inhibited osteoclast formation and partially reversed the bone loss induced by $5 / 6$ nephrectomy in mice through the upregulation of OPG/RANKL.

\section{Introduction}

Renal osteodystrophy is used to describe abnormal changes in bone structure and function, including bone loss and increased bone fragility, in patients with chronic kidney disease (CKD), and is also a measure of CKD-mineral and bone disorder syndrome (1-3). Renal osteodystrophy is found in almost all patients with dialysis-requiring CKD and in the majority of patients with CKD of stages 3-5 (4-6), and contributes to increased risk of fracture. In addition, fracture in patients with end-stage kidney disease often causes increased mortality rates (7-10).

The prevalence of CKD in the US adult population was $11 \%$ in 2003, as revealed by the Third National Health and Nutrition Examination Survey (11). In particular, of those aged $\geq 70$ years, only $26 \%$ had normal kidney function (11). Almost $6 \%$ of patients with CKD suffer from fractures in 5-year-follow up, and this rate is higher in elderly patients (12). Patients with end-stage renal disease in their 40s have an 80 -fold higher risk of hip fracture compared with that of age and gender-matched controls (13). In patients with stage $4 \mathrm{CKD}$, the risk of hip fracture has been reported to be almost 4-fold that of the general population without CKD (14). Thus, the healthcare costs associated with renal osteodystrophy and secondary fracture are substantial (15).

The treatment options for renal osteodystrophy include phosphate binders for lowering high serum phosphorus and maintaining serum calcium, calcitriol or vitamin D analogues for lowering serum parathyroid hormone levels, growth hormone, bisphosphonates and other osteoporosis medications $(2,3)$. However, the effectiveness and feasibility of these treatments are limited due to significantly reduced kidney function. In addition, extraskeletal calcification may be exacerbated by certain therapies, which are used to correct changes in mineral and bone in patients with CKD.

Osthole (7-methoxy-8-isopentenoxycoumarin), a derivative of the Chinese herbal medicine, Fructus Cnidii, has been 
demonstrated to be capable of significantly reversing bone loss and improving the mechanical properties of long bones in ovariectomized rats $(16,17)$. Thus, the present study hypothesized that osthole may also have a protective effect against bone loss in an animal model of renal osteodystrophy. Thus, osthole may be a useful treatment method of CKD-induced bone loss. To confirm this hypothesis and reveal the underlying mechanism, a 5/6 nephrectomy mouse model was established to induce bone loss in mice, and osthole was injected intraperitoneally 1 month following nephrectomy, which had been established for 2 months. Subsequent histomorphlogical analysis was performed to examine bone structure, and in vitro experiments were performed to investigate osthole-regulated osteoclastogenesis.

\section{Materials and methods}

Establishment of the 5/6 nephrectomy mouse model and grouping. The use of animals in the present study was approved by the Shanghai Laboratory Animal Use Committee (Shanghai, China). A total of 40 2-month-old male C57/BL6 mice were obtained from Shanghai SLAC Laboratory Animal Co., Ltd. (Shanghai, China) and were allowed to acclimatize for 1 week. The mice were housed in environmentally controlled animal facilities at $22^{\circ} \mathrm{C}$ with a 12 -h light/dark cycle. The animals were had access to a commercial diet and distilled water ad libitum. CKD was achieved following two surgical procedures. The mice were anesthetized by intraperitoneal injection of $2 \%$ pentobarbital sodium $(40 \mathrm{mg} / \mathrm{kg})$. For the first surgical procedure, a 2-cm right flank incision was made and the left kidney was exposed. The perirenal fat was separated from the kidney, and the upper third and lower third of the kidney were removed using an electrotome. Following compression hemostasis with gelatin for $5 \mathrm{~min}$, the subcutaneous tissues and the skin were sutured. The second surgical procedure was performed 1 week later. The right kidney was exposed using the same procedure as that described above, following which the hilum was ligated and the kidney was excised. The incisions were closed, as described above (18). A total of 30 mice underwent 5/6 nephrectomy, and 12 subsequently succumbed. At 1 month following the second surgical procedure, the remaining 18 mice were randomly divided into two groups. In one group, the mice received daily intraperitoneal injections of $0.15 \mathrm{ml} 1 \mathrm{mg} / \mathrm{ml}$ osthole (dissolved in corn oil; $5 \mathrm{mg} / \mathrm{kg} / \mathrm{day}$ ) for 2 months, and in the second group, the mice received corn oil $(0.15 \mathrm{ml})$ instead of the osthole. Mice in the sham group $(n=10)$ underwent the two surgical procedures with incisions to expose the kidney only and were treated with $0.15 \mathrm{ml}$ corn oil.

Detection of blood urea nitrogen (BUN) and serum creatinine $(\mathrm{Scr})$. The mice were sacrificed by cervical dislocation 1 month following the second surgical procedure following intraperitoneal injection of $2 \%$ pentobarbital sodium $(40 \mathrm{mg} / \mathrm{kg})$, and blood was collected by eyeball removal and transferred into heparinized tubes. The serum was separated by centrifugation at $1,000 \mathrm{xg}$ for $10 \mathrm{~min}$ at $4^{\circ} \mathrm{C}$. The levels of BUN and Scr were measured using a two-site immunoradiometric assay with commercially available kits (Immutopics, Inc., San Clemente, CA, USA).
Table I. Names and sequences of primers used for polymerase chain reaction analysis.

\begin{tabular}{ll}
\hline Gene & \multicolumn{1}{c}{ Sequence } \\
\hline s-actin & F: 5'-GGAGATTACTGCCCTGGCTCCTA-3' \\
& R: 5'-GACTCATCGTACTC CTGCTTGCTG-3' \\
Trap & F: 5'-TTGCGACCATTGTTAGCCACATA-3' \\
& R: 5'-TCAGATCCATAGTGAAA CCGCAAG-3' \\
Mmp9 & F: 5'-CCATGCACTGGGCTTAGATCA-3' \\
& R: 5'-GGCCTTGGGTCAGGCTTAGA-3' \\
Opg & F: 5'-CAGAGCGAAACAC AGTTTG-3' \\
& R: 5'-CACACAGGGTGACATCTATTC-3' \\
Rankl & F: 5'-CAGGTTTGCAGGACTCGAC-3' \\
& R: 5'-AGCAGGGAAGGGTTGGACA-3'
\end{tabular}

Trap, tartrate-resistant acid phosphatase; $\mathrm{Mmp} 9$, matrix metalloproteinase 9; Opg, osteoprotegerin; Rankl, receptor activator for nuclear factor- $\kappa \mathrm{B}$ ligand; F, forward; R, reverse.

Three-dimensional $(3 D)$ reconstruction analyses. The lumbar 4 (L4) vertebrae from the mice in all groups were dissected 2 months following treatment and fixed in $4 \%$ paraformaldehyde for $24 \mathrm{~h}$ at $4^{\circ} \mathrm{C}$, followed by washing in flowing water for $2 \mathrm{~h}$. Subsequently, 3D reconstruction analyses were performed using a Micro-CT 80 scan machine (Scanco Medical AG, Bassersdorf, Switzerland). The vertebrae underwent fine scanning in 400-500 slices with $10 \mu \mathrm{m}$ slice increments. The X-ray source voltage was $55 \mathrm{kVp}$, the source current was $72 \mu \mathrm{A}$ and the integration time was $400 \mathrm{msec}$. A reconstruction of the bitmap data set was used to construct the 3D images of the spongy bone using the built-in software (Scanco Holding AG, Brüttisellen, Switzerland.

Histological evaluation. The L4 vertebrae were subjected to histological analysis in order to reveal the pathological structure. The vertebrae were fixed in $4 \%$ paraformaldehyde, decalcified, dehydrated and embedded in paraffin. Serial mid-sagittal sections (4- $\mu$ m thick) of the vertebrae were cut and stained with hematoxylin and eosin (H\&E). Morphometric analysis was performed using a light microscope (Olympus BX50; Olympus Corporation, Tokyo, Japan) with a camera (Olympus DP71; Olympus Corporation) and Image Pro Plus 6.0 software (Media Cybernetics, Inc. (Rockville, MD, USA).

Immunohistochemical (IHC) staining. The L4 vertebrae were collected and fixed in $4 \%$ paraformaldehyde, decalcified, dehydrated and embedded in paraffin. Serial mid-sagittal sections (4- $\mu \mathrm{m}$ thick) were cut. Endogenous peroxidase was blocked in $3 \%$ hydrogen peroxide/methanol for $15 \mathrm{~min}$ at room temperature, followed by antigen retrieval in $20 \mu \mathrm{g} / \mathrm{ml}$ proteinase $\mathrm{K}$ for $10 \mathrm{~min}$ at $37^{\circ} \mathrm{C}$. Following blocking in $5 \%$ bovine serum albumin (from IHC kit, Wuhan Boster Biological Technology, Co., Ltd., Wuhan, China) at room temperature for $30 \mathrm{~min}$, the slices were incubated with primary antibody diluted in $2 \%$ goat serum (Wuhan Boster Biological Technology, Co., Ltd.), 
A

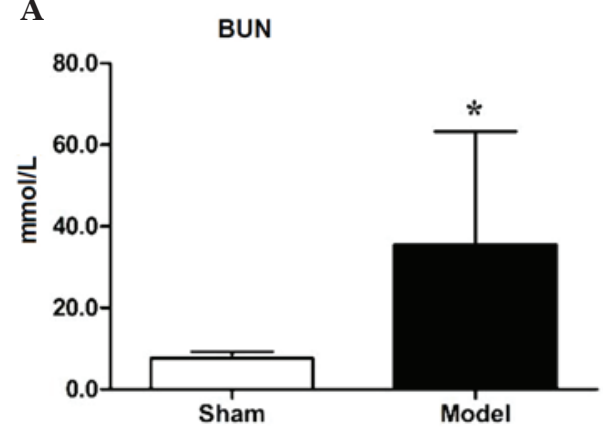

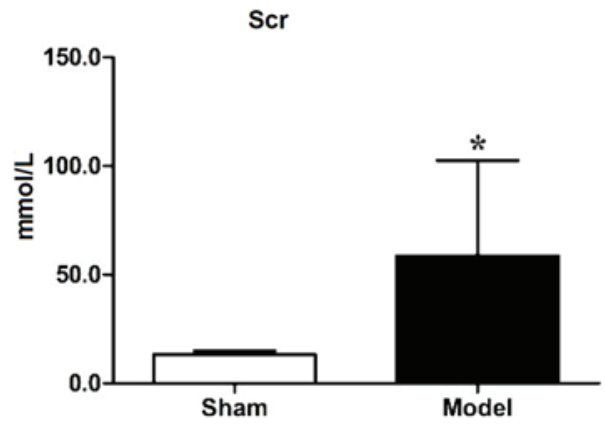

Figure 1. Kidney function is reduced in 5/6 nephrectomy mice. (A) Compared with the sham group, 1 month following the second surgical procedure in the $5 / 6$ nephrectomy model, the expression of BUN in the 5/6 nephrectomy group was increased significantly ( $7.64 \pm 1.60$, vs. $35.52 \pm 27.76$ mmol/1, respectively). (B) The expression of Scr $(13.33 \pm 1.65$, vs. $58.73 \pm 43.80 \mu \mathrm{mol} / 1)$ was also significantly increased. ${ }^{*} \mathrm{P}<0.05$, compared with the sham group (n=6). BUN, blood urea nitrogen; Scr, serum creatinine.

including rabbit polyclonal anti-cathepsin $\mathrm{K}(1: 100$; Abcam, Cambridge, MA, USA; ab19027), rabbit polyclonal anti-NFATc1 (1:100; Santa Cruz Biotechnology, Inc., Dallas, TX, USA; cat. no. sc-13033) and rabbit anti-c-Fos (1:100 dilution; Santa Cruz Biotechnology, Inc.; cat. no. sc-253), at $4^{\circ} \mathrm{C}$ overnight. The slices were then incubated in 1:200 biotinylated goat anti-rabbit secondary antibody (from IHC kit, Wuhan Boster Biological Technology, Co., Ltd.) for $15 \mathrm{~min}$ at $37^{\circ} \mathrm{C}$, followed by incubation in 1:250 horseradish peroxidase-streptavidin for $10 \mathrm{~min}$ at $37^{\circ} \mathrm{C}$. Following staining with 3,3'-Diaminobenzidine solution, the slices were counterstained in hematoxylin, dehydrated, cleared and mounted. Negative control slices were incubated in $2 \%$ goat serum instead of the primary antibodies. The images were captured using a light microscope (Olympus BX50) with a camera (Olympus DP71) and Image Pro Plus 6.0 software.

Calvarial osteoblast isolation and treatment. Mouse pups $(\mathrm{n}=8$; age, 3 days) were obtained from Shanghai SLAC Laboratory Animal Co., Ltd. and sacrificed by cervical dislocation on arrival at the laboratory. The soft tissue and periosteal layers were carefully removed and placed in $70 \%$ alcohol. The calvarial tissue was digested in $1 \mathrm{mg} / \mathrm{ml}$ collagenase $\mathrm{A} / \alpha$-minimum essential media ( $\alpha$-MEM; BioSera, Nauille, France) for $45 \mathrm{~min}$ in a $37^{\circ} \mathrm{C}$ water bath, and the enzyme solution was replaced every $15 \mathrm{~min}$. Following the third digestion, the enzyme and cell mixture were filtered and collected. The remaining calvarial tissue was digested in enzyme solution for another $15 \mathrm{~min}$, and the cells were collected. Following three repetitions, the collected cells were mixed, centrifuged at $300 \mathrm{x}$ g for $5 \mathrm{~min}$ at room temperature and resuspended in complete $\alpha$-MEM with $50 \mu \mathrm{g} / \mathrm{ml}$ ascorbic acid. Calvarial osteoblasts were plated into 12-well culture plates at a density of $1 \times 10^{5}$ cells/well. For osthole treatment, the calvarial osteoblasts were cultured in $\alpha$-MEM without fetal bovine serum (FBS; BioSera) overnight at $37^{\circ} \mathrm{C}$ and treated with $0.1,1$ and $10 \mu \mathrm{M}$ osthole/dimethyl sulphoxide (DMSO) in 10\% FBS/Dulbecco's modified Eagle's medium (BioSera), respectively, for 2 days at $37^{\circ} \mathrm{C}$. DMSO without osthole was used in the control group.

In vitro osteoclast differentiation assay. Bone marrow cells were isolated from the femurs and tibias of 4 male 1-month-old wild-type mice (Shanghai SLAC Laboratory Animal Co., Ltd.). The mice were sacrificed by cervical dislocation on arrival at the laboratory following anesthesia with $2 \%$ sodium pentobarbital $(40 \mathrm{mg} / \mathrm{kg}$ ), and were plated into 24 -well culture plates at a density of $4 \times 10^{5}$ cells/well with $\alpha$-MEM supplemented with $10 \%$ FBS. The cells were treated with macrophage colony-stimulating factor (M-CSF; $20 \mathrm{ng} / \mathrm{ml}$ ) at $37^{\circ} \mathrm{C}$ for 3 days, and were then switched to differentiation medium with $10 \mathrm{ng} / \mathrm{ml} \mathrm{M-CSF}$ and $50 \mathrm{ng} / \mathrm{ml}$ receptor activator for nuclear factor- $\kappa$ B ligand (RANKL) at $37^{\circ} \mathrm{C}$ for a further 7 days. For osthole treatment, the bone marrow cells were cultured in $\alpha$-MEM without FBS overnight at $37^{\circ} \mathrm{C}$ and treated with $0.1,1$ and $10 \mu \mathrm{M}$ osthole/DMSO in $10 \% \mathrm{FBS} / \alpha-\mathrm{MEM}$ at $37^{\circ} \mathrm{C}$, respectively, for 7 days. DMSO without osthole was used in the control group. Tartrate-resistant acid phosphatase (TRAP) staining was performed using a TRAP assay kit (Sigma-Aldrich; Thermo Fisher Scientific, Inc., Waltham, MA, USA).

Reverse transcription-quantitative polymerase chain reaction (RT-qPCR) analysis. Total RNA was isolated from the L4 vertebrae using TRIzol reagent, and from the primary cultured cells using an RNeasy mini kit (Invitrogen; Thermo Fisher Scientific, Inc.). Reverse transcription was performed using an iScript cDNA Synthesis kit (Qiagen, Suzhou, China), and cDNA was amplified by PCR using a total volume of $20 \mu \mathrm{l}$ reaction system containing $10 \mu \mathrm{l}$ SYBR Green Master Mix (Bio-Rad Laboratories, Inc., Hercules, CA, USA), $1 \mu 1$ of the diluted (1:5) cDNA and $10 \mathrm{pM}$ of the forward and reverse primers specific for the genes (Table I). The PCR thermocycling conditions were as follows: $95^{\circ} \mathrm{C}$ for $10 \mathrm{~min}$; 40 cycles of $95^{\circ} \mathrm{C}$ for $10 \mathrm{sec}, 58^{\circ} \mathrm{C}$ for $15 \mathrm{sec}$, and $72^{\circ} \mathrm{C}$ for $20 \mathrm{sec}$. The $\mathrm{Cq}$ values were recorded and used to calculate relative quantities in the groups as previously described (19).

Statistical analysis. Data are presented as the mean with $95 \%$ confidence intervals. Statistical analyses were performed using one-way analysis of variance followed by Dunnett's test. For experiments involving two groups, Student's $t$-test (unpaired) was performed. $\mathrm{P}<0.05$ was considered to indicate a statistically significant difference.

\section{Results}

Evaluation of renal insufficiency. To verify the establishment of the 5/6 nephrectomy model, the levels of BUN and Scr 


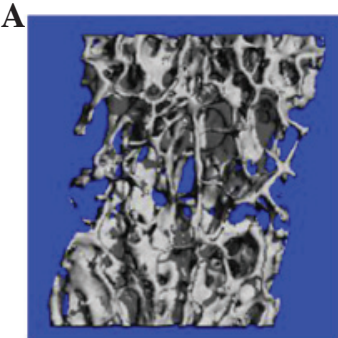

Sham

B

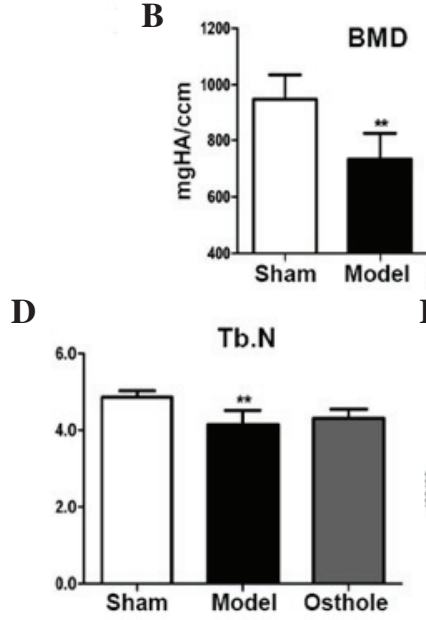

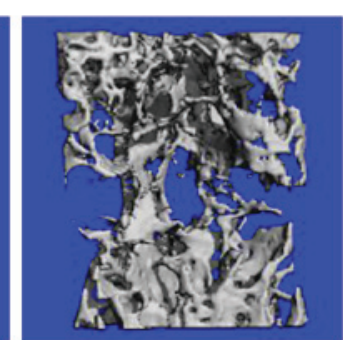

Model

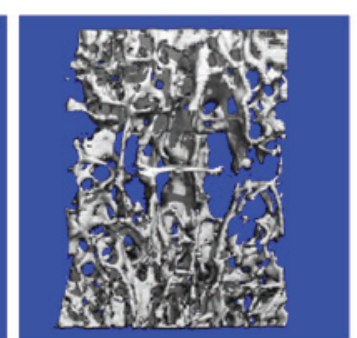

Osthole
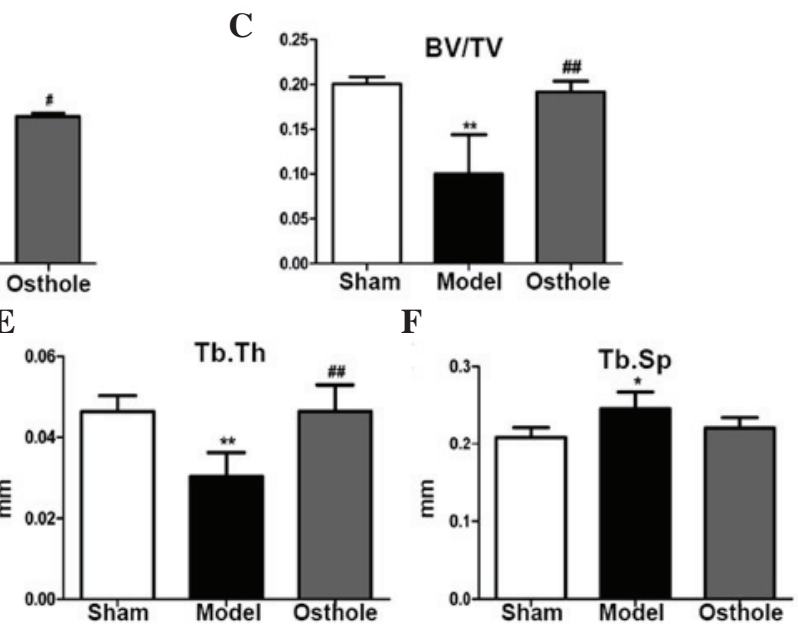

Figure 2. Bone loss in 5/6 nephrectomy mice is rescued by treatment with osthole. The L4 vertebrae of the mice in the sham, model and osthole group were harvested 2 months following treatment, and micro CT scanning and reconstruction was performed. (A) Micro CT reconstruction of L4 vertebrae. Decreased (B) BMD, (C) BV/TV, (D) Tb.N and (E) Tb.Th, and increased (F) Tb.Sp of the L4 vertebrae were shown in the 5/6 nephrectomy group, compared with the sham group. Following treatment with osthole for 2 months, (B) BMD, (C) BV/TV and (E) Tb.Th of the L4 vertebrae were significantly increased, compared with the 5/6 nephrectomy group. No significant changes in (D) Tb.N or (F) Tb.Sp were found. "P<0.05 and ${ }^{* * *} \mathrm{P}<0.01$, compared with the sham group; ${ }^{*} \mathrm{P}<0.05$ and ${ }^{\# \#} \mathrm{P}<0.01$, compared with the model group $(\mathrm{n}=6)$. BMD, bone mineral density; BV/TV, bone volume/total volume; Tb.N, trabecular number; Tb.Th, trabecular thickness; Tb.Sp, trabecular separation.

in the sham group and nephrectomy group were measured 1 month following the second surgical procedure. Compared with the sham group, the level of BUN in the nephrectomy model group was increased significantly $(7.64 \pm 1.60$, vs. $35.52 \pm 27.76 \mathrm{mmol} / 1$, respectively; $\mathrm{P}<0.05)$, as was the level of Scr $(13.33 \pm 1.65$, vs. $58.73 \pm 43.80 \mu \mathrm{mol} / 1$, respectively $(\mathrm{P}<0.05)$, as shown in Fig. $1 \mathrm{~A}$ and $\mathrm{B}$, indicating that the $5 / 6$ nephrectomy model had been established in the mice.

Bone loss is rescued in 5/6 nephrectomy mice treated with osthole. To observe the overall effects of osthole on bone loss in the 5/6 nephrectomy mice, L4 vetrebrae were harvested 2 months following osthole treatment, and micro CT scanning and reconstruction were performed (Fig. 2A). The micro $\mathrm{CT}$ analysis showed a reduction in BMD in the $\mathrm{L} 4$ vertebrae of the $5 / 6$ nephrectomy group, compared with the sham group (732.766 \pm 92.240 , vs. $948.974 \pm 86.823$, respectively; $\mathrm{P}<0.01$; Fig. $2 \mathrm{~B}$ ) and the same was true for bone volume/total volume (BV/TV; $0.100 \pm 0.044$, vs. $0.201 \pm 0.008$; $\mathrm{P}<0.01$; Fig. 2C). In addition, trabecular number (Tb.N; $4.140 \pm 0.376$, vs. $4.860 \pm 0.166 ; \mathrm{P}<0.01$; Fig. $2 \mathrm{D})$ and trabecular thickness (Tb.Th; 0.030 \pm 0.006 , vs. $0.0464 \pm 0.004$; $\mathrm{P}<0.01$; Fig. 2E) were decreased in the 5/6 nephrectomy group, compared with the sham group, whereas trabecular separation (Tb.Sp; $0.245 \pm 0.022$, vs. $0.208 \pm 0.012$; P $<0.05$; Fig. $2 \mathrm{~F}$ ) was significantly increased, compared with the sham group. Following treatment with osthole for 2 months, the BMD
(923.356 \pm 11.916 , vs. $732.766 \pm 92.240 ; \mathrm{P}<0.05 ;$ Fig. $2 \mathrm{~B})$ and BV/TV $(0.192 \pm 0.012$, vs. $0.100 \pm 0.044 ; \mathrm{P}<0.01$; Fig. $2 \mathrm{C})$ of the L4 vertebrae were increased, compared with the $5 / 6$ nephrectomy group. A significant increase in Tb.Th was also observed $(0.046 \pm 0.007$, vs. $0.030 \pm 0.006$; $\mathrm{P}<0.01$; Fig. $2 \mathrm{E})$. However, no significant changes were found in Tb.N $(4.313 \pm 0.235$, vs. $4.140 \pm 0.376$; P $>0.05$; Fig. 2D) or Tb.Sp $(0.220 \pm 0.014$, vs. $0.245 \pm 0.022$, P $>0.05$; Fig. $2 \mathrm{~F}$ ). Taken together, these data suggested that osthole partially rescued the bone loss induced by $5 / 6$ nephrectomy in mice.

Osteoclast numbers are reduced in 5/6 nephrectomy mice treated with osthole. Changes in the microstructure of the L4 vertebrae were revealed using $\mathrm{H} \& \mathrm{E}$ staining. The trabecular bone of the L4 vertebrae from the $5 / 6$ nephrectomy was reduced in thickness and quantity at 3 months post-5/6 nephrectomy, confirming that bone loss was induced (Fig. 3A). By contrast, the structure of the trabecular bone of the L4 vertebrae in the osthole-treated 5/6 nephrectomy mice was markedly improved, as shown by the histological data (Fig. 3A), which was consistent with the results of the micro CT analysis (Fig. 2A). To determine whether osteoclast formation was altered, TRAP staining was performed using sections from $5 / 6$ nephrectomy mice and osthole-treated 5/6 nephrectomy mice. In the L4 vertebrae of the sham mice, only a few osteoclasts were found to be TRAP-positive on the surface of the trabecular bone in the $5 / 6$ nephrectomy mice; however, the number of osteoclasts 
A

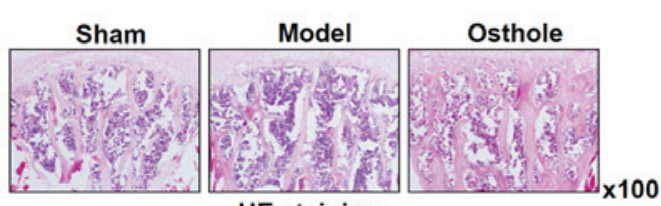

HE staining

C

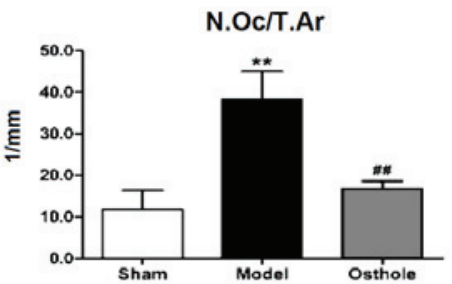

E

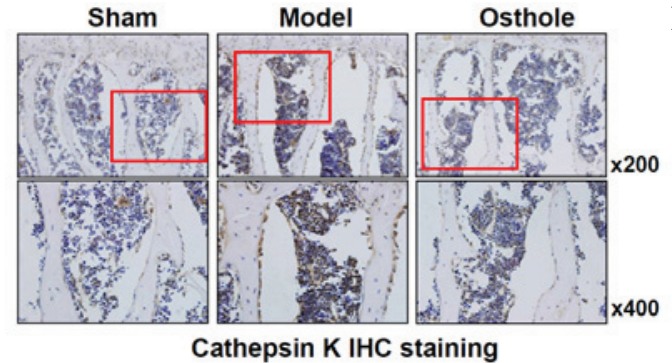

B

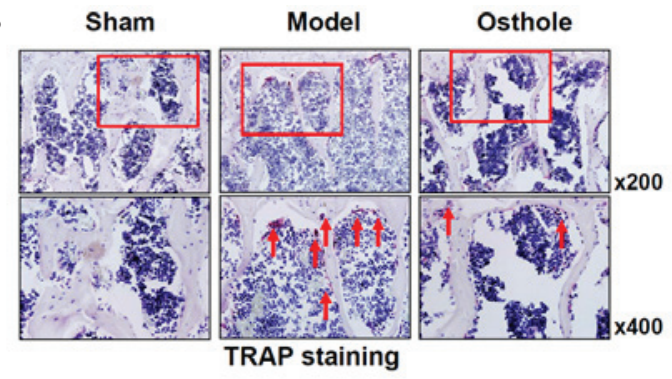

D

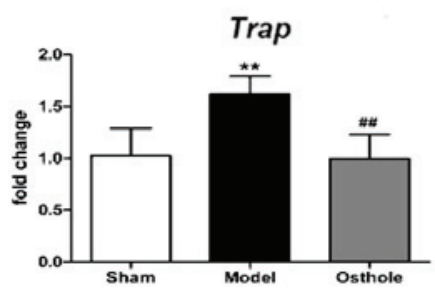

F

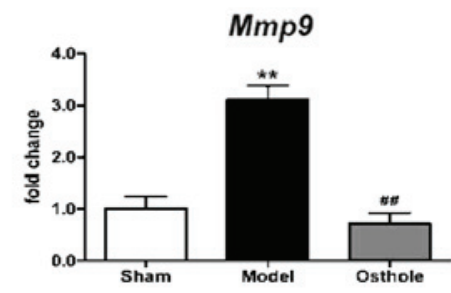

Figure 3. Osteoclast number is reduced in 5/6 nephrectomy mice treated with osthole. (A) HE staining showed that the trabecular bone of the L4 vertebrae was reduced in thickness and quantity in the 5/6 nephrectomy mice, which was improved by osthole treatment (magnification, x100). (B) TRAP staining. (C) Quantification of N.Oc/T.Ar and reverse transcription-quantitative polymerase chain reaction analysis for (D) Trap showed increased osteoclast numbers in the L4 vertebrae of the 5/6 nephrectomy mice, compared with the sham mice, and this was decreased in the osthole-treated 5/6 nephrectomy mice, compared with the 5/6 nephrectomy mice. (E) cathepsin K and (F) Mmp9 in the L4 vertebrae were expressed at high levels following 5/6 nephrectomy, and these increases were partially inhibited by osthole. ${ }^{* *} \mathrm{P}<0.01$, compared with the sham group; ${ }^{\# \#} \mathrm{P}<0.01$, compared with the model group. Red arrows indicate TRAP-positive osteoclasts and red boxes show area magnifiied in the image below. HE, hematoxylin and eosin; N.Oc/T.Ar, osteoclast number/trabecular bone area; IHC, immunohistochemical; TRAP, tartrate-resistant acid phosphatase; $M m p 9$, matrix metalloproteinase 9.

were significantly increased, compared with the sham group. In the osthole-treated 5/6 nephrectomy mice, there were only a few osteoclasts, similar to the sham group (Fig. 3B).

Quantification of the TRAP staining also showed an increase in the number of osteoclasts/trabecular bone area in the L4 vertebrae of the 5/6 nephrectomy mice, compared with the sham mice. Decreases in osteoclast number/trabecular bone area were observed in the L 4 vertebrae of the osthole-treated mice, compared with the 5/6 nephrectomy mice (Fig. 3C). Similarly, the expression of Trap was increased in the L4 vertebrae of the 5/6 nephrectomy mice, and was reversed to a level similar to that in the sham group in the osthole-treated mice (Fig. 3D). For further confirmation, changes in the expression levels of cathepsin $\mathrm{K}$ and $M m p 9$, markers of osteoclast formation, were revealed using IHC staining and RT-qPCR analysis, respectively. The expression levels of cathepsin $\mathrm{K}$ and $\mathrm{Mmp} 9$ in the L4 vertebrae were higher following 5/6 nephrectomy, and these increases were partially inhibited by treatment of the 5/6 nephrectomy mice with osthole (Fig. 3E and F).

Osthole inhibits osteoclast formation through regulation of the expression of OPG/RANKL in osteoblasts. To confirm the effect of osthole on osteoclast formation, primary bone marrow cells were cultured for osteoclast formation and treated with osthole for 7 days. Osteoclast formation was shown using TRAP staining. Osteoclast formation was markedly inhibited by osthole treatment in a dose-dependent manner (Fig. 4A). To determine the mechanisms underlying the regulation of osteoclast formation in the 5/6 nephrectomy mice and osthole treated 5/6 nephrectomy mice, RT-qPCR analysis was performed to determine the expression levels of Opg and Rankl in the L4 vertebrae. The expression of Opg in the L4 vertebrae of the 5/6 nephrectomy mice was markedly decreased, compared with that of the sham group, however, no significant alteration in the expression of Rankl was observed. Therefore, the $O p g / R a n k l$ ratio was decreased significantly, which induced osteoclast formation in the $5 / 6$ nephrectomy mice. In the L4 vertebrae of the osthole-treated 5/6 nephrectomy mice, the expression of $O p g$ was increased and the expression of Rankl was decreased, compared with the 5/6 nephrectomy mice. Therefore, increased Opg/Rankl may be responsible for reduced osteoclast formation following osthole treatment (Fig. 4B-D). To confirm the changes in Opg and Rankl in vitro, primary calvarial osteoblasts were cultured and treated with osthole for 2 days. The expression levels of Opg and Rankl were detected in osteoblasts, respectively. Similar to the in vivo results, the expression of Opg was upregulated and the expression of Rankl was downregulated 

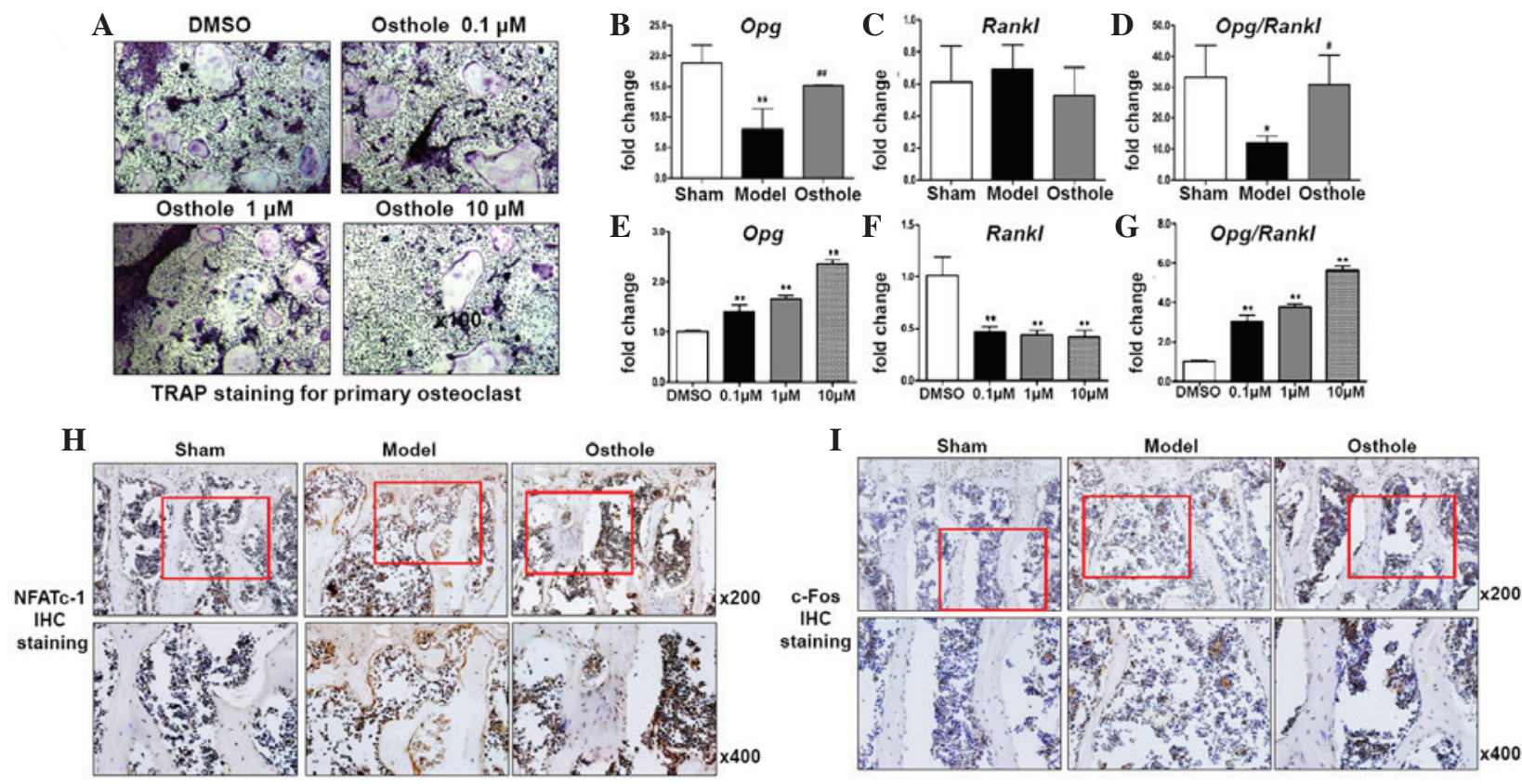

Figure 4. Osthole inhibits osteoclast formation by regulating the expression of OPG/RANKL in osteoblasts. (A) Primary bone marrow cells were cultured for osteoclast formation and treated with osthole for 7 days. Osteoclast formation was shown using TRAP staining and was decreased by osthole in a dose-dependent manner. Reverse transcription-quantitative polymerase chain reaction analysis showed a significant decrease in the expression of (B) $O p g$ in the L4 vertebrae of 5/6 nephrectomy mice, compared with the sham group. (C) Rankl did not change significantly. The decreased Opg and (D) Opg/Rankl were partially inhibited by osthole. Primary calvarial osteoblasts were cultured and treated with osthole for 2 days. (E) Expression of $O p g$ was upregulated and (F) Rankl was downregulated by osthole. (G) Opg/Rankl was also upregulated by osthole in a dose-dependent manner. IHC staining showed increased (H) NFATc1 and (I) c-Fos in the L4 vertebrae of the $5 / 6$ nephrectomy mice, compared with sham group, and this was inhibited by osthole. ${ }^{*} \mathrm{P}<0.05$ and ${ }^{* *} \mathrm{P}<0.01$, compared with the sham group; ${ }^{\#} \mathrm{P}<0.05$ and ${ }^{\# \#} \mathrm{P}<0.01$, compared with the model group. Red boxes indicate the area was magnified for the image below. TRAP, tartrate-resistant acid phosphatase; opg, osteoprotegerin; rankl, receptor activator for nuclear factor- $\kappa \mathrm{B}$ ligand; NFATc-1, nuclear factor of activated T-cells, cytoplasmic-1; IHC, immunohistochemical.

by treatment with osthole in a dose-dependent manner. The Opg/Rankl ratio was also upregulated (Fig. 4E-G). These results suggested that osthole treatment increased the expression of Opg in osteoblasts, therefore osteoblasts could secrete more OPG protein into the surrounding microenvironment. NFATc-1 and c-Fos are the key regulators of osteoclast differentiation upon RANKL induction. The IHC staining for the expression of NFATc-1 and c-Fos in the L4 vertebrae showed increased expression levels of NFATc-1 and c-Fos in the 5/6 nephrectomy mice, and inhibition of the induced expression levels of NFATc-1 and c-Fos following treatment with osthole (Fig. 4H and I).

\section{Discussion}

Osthole is a coumarin derivative present in several plants, including Angelica pubescens and Cnidium monnieri $(20,21)$. These plants have been used for the treatment of primary and secondary osteoporosis in traditional Chinese medicine. Previous studies have confirmed that osthole is capable of significantly reversing ovariectomy-induced bone loss in rats $(16,17)$. In the present study, osthole was found to be effective in the treatment of bone loss in 5/6 nephrectomy mice, and the mechanism were correlated with osteoclast inhibition.

Bone resorption is abnormally high in the late stage of CKD (22,23). Bone loss (24) and marked bone resorption have also been observed in a 5/6 nephrectomy model $(25,26)$, which is consistent with the results of the present study. In the present study, osthole treatment partially reversed the bone loss induced by 5/6 nephrectomy in the mice. Histological analysis revealed that the increase of osteoclast formation in the $5 / 6$ nephrectomy mice was rescued by osthole treatment, shown by decreased expression levels of Trap, cathepsin $K$ and $M m p 9$, suggesting that the enhanced bone resorption induced by nephrectomy in the mice was prohibited by osthole. The in vitro experiments also confirmed that the osteoclast formation of primary bone marrow cells was reduced when the cells were cultured in the presence of osthole.

Multinucleated osteoclasts differentiate from hematopoietic progenitors of the monocyte/macrophage lineage. Osteoclast formation is predominantly regulated by the ratio of OPG/RANKL. RANKL mediates the differentiation, activation and survival of osteoclasts by binding to its receptor, RANK, which is a member of the tumor necrosis factor receptor family. OPG disturbs the binding between RANK and RANKL and exerts a function opposite to that of RANKL (27-31). A previous study showed that inhibiting RANKL with OPG-Fc reverses the high bone turnover and low BMD induced by 5/6 nephrectomy, suggesting that RANKL may offer potential as an important therapeutic target to protect bone loss in patients with CKD (32). Osthole may act like an estrogen (33) and regulate OPG/RANKL through estrogen receptor $\alpha(34,35)$. Osthole has also been shown to regulate the ratio of OPG/RANKL by upregulating the expression of OPG and downregulating the expression of RANKL in vitro (36), suggesting that osthole may prohibit osteoclast 
formation through the regulation of OPG/RANKL in the 5/6 nephrectomy mouse model. The results of the RT-qPCR analysis in the present study of the expression levels of $O p g$ and Rankl in the L4 vertebrae suggested the in vivo function of osthole on Opg/Rankl. The 5/6 nephrectomy decreased the expression of $O p g$ in the vertebrae of the mice, whereas the expression of Rankl remained unchanged. Osthole reversed the reduction of $O p g$ and reduced the expression of $R a n k l$, leading to reversal of the reduction of $\mathrm{Opg} / \mathrm{Rankl}$ and resulting in the inhibition of osteoclast formation.

Osteoblast and bone marrow stromal cells are important sources of OPG and RANKL. They are involved in osteoclast differentiation in the bone marrow microenvironment through a mechanism of cell-to-cell interaction with osteoclast progenitors (27-29). The in vitro experiments in the present study showed that osthole increased the expression of OPG and decreased the expression of RANKL in primary osteoblasts. NFATc1 is the key regulator of osteoclast differentiation. Upon RANKL/RANK binding, NFATc1 can be induced through the TRAF6-NF- $\kappa$ B and c-Fos pathways. c-Fos, together with continuously activated calcium signaling, is also crucial for auto-amplification of the NFATc1 signal (37). NFATc1 further regulates osteoclast-specific gene transcription in cooperation with other transcription factors (38). In the present study, NFATc1 and c-Fos were downregulated following treatment with osthole in vivo and in vitro. Taken together, the results demonstrated that osthole upregulated the expression of OPG and downregulated the expression of RANKL in osteoblasts, and prohibited the induction of NFATc1 signaling in hematopoietic progenitors of the monocyte/macrophage lineage. The expression of osteoclast-specific genes was downregulated and osteoclast formation was prohibited.

In conclusion, the present study provided evidence that osthole partially rescued bone loss of vertebrae induced by $5 / 6$ nephrectomy in mice through the inhibition of osteoclast formation. Mechanistically, osthole treatment upregulated OPG and downregulated RANKL in osteoblasts and stromal cells, and further inhibited the expression of NFATc1 and c-Fos in osteoclasts. Thus, osthole may be a potential candidate therapeutic agent for high turnover of bone loss induced by menopause, secondary hyperparathyroidism and glucocorticoid intake.

\section{Acknowledgements}

This study was supported in part by the National Natural Science Foundation of China (grant nos. 81403239 and 81503590), the Shanghai Natural Science Foundation (grant no. 12ZR1450400) and the Program for Innovative Research Team (grant no. 2015RA4002). The authors would like to thank Professor Di Chen (Rush University, Chicago, IL, USA) for assisting with the language modification of this manuscript.

\section{References}

1. Moe S, Drüeke T, Cunningham J, Goodman W, Martin K, Olgaard K, Ott S, Sprague S, Lameire N and Eknoyan G; Kidney Disease: Improving Global Outcomes (KDIGO): Definition, evaluation, and classification of renal osteodystrophy: A position statement from Kidney Disease: Improving Global Outcomes (KDIGO). Kidney Int 69: 1945-1953, 2006.
2. Uhlig K, Berns JS, Kestenbaum B, Kumar R, Leonard MB, Martin KJ, Sprague SM and Goldfarb S: KDOQI US commentary on the 2009 KDIGO clinical practice guideline for the diagnosis, evaluation and treatment of CKD-Mineral and Bone Disorder (CKD-MBD). Am J Kidney Dis 55: 773-799, 2010.

3. Kidney Disease: Improving Global Outcomes (KDIGO) CKD-MBD Work Group: KDIGO clinical practice guideline for the diagnosis, evaluation, prevention, and treatment of Chronic Kidney Disease-Mineral and Bone Disorder (CKD-MBD). Kidney Int Suppl (Suppl): S1-S130, 2009.

4. Sprague SM: The role of the bone biopsy in the diagnosis of renal osteodystrophy. Semin Dial 13: 152-155, 2000.

5. Barreto FC, Barreto DV, Moyses RM, Neves CL, Jorgetti V, Draibe SA, Canziani ME and Carvalho AB: Osteoporosis in hemodialysis patients revisited by bone histomorphometry: A new insight into an old problem. Kidney Int 69: 1852-1857, 2006.

6. Malluche HH and Monier-Faugere MC: Renal osteodystrophy: What's in a name? Presentation of a clinically useful new model to interpret bone histologic findings. Clin Nephrol 65: 235-242, 2006.

7. Go AS, Chertow GM, Fan D, McCulloch CE and Hsu CY: Chronic kidney disease and the risks of death, cardiovascular events, and hospitalization. N Engl J Med 351: 1296-1305, 2004.

8. Block GA, Hulbert-Shearon TE, Levin NW and Port FK: Association of serum phosphorus and calcium $\mathrm{x}$ phosphate product with mortality risk in chronic hemodialysis patients: A national study. Am J Kidney Dis 31: 607-617, 1998.

9. Kestenbaum B, Sampson JN, Rudser KD, Patterson DJ, Seliger SL, Young B, Sherrard DJ and Andress DL: Serum phosphate levels and mortality risk among people with chronic kidney disease. J Am Soc Nephrol 16: 520-528, 2005.

10. Keith DS, Nichols GA, Gullion CM, Brown JB and Smith DH: Longitudinal follow-up and outcomes among a population with chronic kidney disease in a large managed care organization. Arch Intern Med 164: 659-663, 2004.

11. Coresh J, Astor BC, Greene T, Eknoyan G and Levey AS: Prevalence of chronic kidney disease and decreased kidney function in the adult US population: Third National Health and Nutrition Examination Survey. Am J Kidney Dis 41: 1-12, 2003.

12. Chang NT, Lee YH, Hsu JC, Chan CL, Huang GS, Renn JH and Yang NP: Epidemiological study of orthopedic injuries in hemodialysis patients in Taiwan: A fixed cohort survey, 2004-2008. Clin Interv Aging 8: 301-308, 2013.

13. Alem AM, Sherrard DJ, Gillen DL, Weiss NS, Beresford SA, Heckbert SR, Wong C and Stehman-Breen C: Increased risk of hip fracture among patients with end-stage renal disease. Kidney Int 58: 396-399, 2000.

14. Dooley AC, Weiss NS and Kestenbaum B: Increased risk of hip fracture among men with CKD. Am J Kidney Dis 51: 38-44, 2008.

15. Schumock GT and Sprague SM: Clinical and economic burden of fractures in patients with renal osteodystrophy. Clin Nephrol 67: 201-208, 2007.

16. Li XX, Hara I and Matsumiya T: Effects of osthole on postmenopausal osteoporosis using ovariectomized rats; comparison to the effects of estradiol. Biol Pharm Bull 25: 738-742, 2002.

17. Tang DZ, Hou W, Zhou Q, Zhang M, Holz J, Sheu TJ, Li TF, Cheng SD, Shi Q, Harris SE, et al: Osthole stimulates osteoblast differentiation and bone formation by activation of beta-catenin-BMP signaling. J Bone Miner Res 25: 1234-1245, 2000.

18. Sangidorj O, Yang SH, Jang HR, Lee JP, Cha RH, Kim SM, Lim CS and Kim YS: Bone marrow-derived endothelial progenitor cells confer renal protection in a murine chronic renal failure model. Am J Physiol Renal Physiol 299: F325-F335, 2010.

19. Schmittgen TD, Zakrajsek BA, Mills AG, Gorn V, Singer MJ and Reed MW: Quantitative reverse transcription-polymerase chain reaction to study mRNA decay: Comparison of endpoint and real-time methods. Anal Biochem 285: 194-204, 2000.

20. Chen YF, Tsai HY and Wu TS: Anti-inflammatory and analgesic activities from roots of Angelica pubescens. Planta Med 61: 2-8, 1995.

21. Ko FN, Wu TS, Liou MJ, Huang TF and Teng CM: Vasorelaxation of rat thoracic aorta caused by osthole isolated from Angelica pubescens. Eur J Pharmacol 219: 29-34, 1992.

22. Malluche HH, Ritz E, Lange HP, Kutschera L, Hodgson M, Seiffert U and Schoeppe W: Bone histology in incipient and advanced renal failure. Kidney Int 9: 355-362, 1976. 
23. Kaye M, Zucker SW, Leclerc YG, Prichard S, Hodsman AB and Barré PE: Osteoclast enlargement in endstage renal disease. Kidney Int 27: 574-581, 1985 .

24. Tomat A, Gamba CA, Mandalunis P, De Grandi MC, Somoza J, Friedman $\mathrm{S}$ and Zeni S: Changes in bone volume and bone resorption by olpadronate treatment in an experimental model of uremic bone disease. J Musculoskelet Neuronal Interact 5: 174-181, 2005.

25. Kawaguchi Y, Kawashima H, Ueno K, Izawa Y, Makita T, Kurozumi S, Hashimoto Y, Yamamoto M, Kimura Y, Imamura $\mathrm{N}$, et al: Effect of 1 alpha-hydroxyvitamin D3 in rats with experimental renal osteodystrophy. Endocrinol Jpn 26 (Suppl): S73-S79, 1979.

26. Moscovici A, Bernheim J, Popovtzer MM and Rubinger D: Renal osteodystrophy in rats with reduced renal mass. Nephrol Dial Transplant 11 (Suppl 3): S146-S152, 1996.

27. Udagawa N, Takahashi N, Yasuda H, Mizuno A, Itoh K, Ueno Y, Shinki T, Gillespie MT, Martin TJ, Higashio K and Suda T: Osteoprotegerin produced by osteoblasts is an important regulator in osteoclast development and function. Endocrinology 141: 3478-3484, 2000.

28. Gori F, Hofbauer LC, Dunstan CR, Spelsberg TC, Khosla S and Riggs BL: The expression of osteoprotegerin and RANK ligand and the support of osteoclast formation by stromal-osteoblast lineage cells is developmentally regulated. Endocrinology 141: 4768-4776, 2000.

29. Yasuda H, Shima N, Nakagawa N, Yamaguchi K, Kinosaki M Goto M, Mochizuki SI, Tsuda E, Morinaga T, Udagawa N, et al: A novel molecular mechanism modulating osteoclast differentiation and function. Bone 25: 109-113, 1999.

30. Nakashima T, Hayashi M and Takayanagi H: New insights into osteoclastogenic signaling mechanisms. Trends Endocrinol Metab 23: 582-590, 2012.

31. Yasuda H, Shima N, Nakagawa N, Yamaguchi K, Kinosaki M, Mochizuki S, Tomoyasu A, Yano K, Goto M, Murakami A, et al: Osteoclast differentiation factor is a ligand for osteoprotegerin/osteoclastogenesis-inhibitory factor and is identical to TRANCE/RANKL. Proc Natl Acad Sci USA 95: 3597-3602, 1998
32. Padagas J, Colloton M, Shalhoub V, Kostenuik P, Morony S, Munyakazi L, Guo M, Gianneschi D, Shatzen E, Geng Z, et al: The receptor activator of nuclear factor-kappaB ligand inhibitor osteoprotegerin is a bone-protective agent in a rat model of chronic renal insufficiency and hyperparathyroidism. Calcif Tissue Int 78: 35-44, 2006.

33. Hsieh MT, Hsieh CL, Wang WH, Chen CS, Lin CJ and Wu CR: Osthole improves aspects of spatial performance in ovariectomized rats. Am J Chin Med 32: 11-20, 2004.

34. Lindberg MK, Erlandsson M, Alatalo SL, Windahl S, Andersson G, Halleen JM, Carlsten H, Gustafsson JA and Ohlsson C: Estrogen receptor alpha, but not estrogen receptor beta, is involved in the regulation of the OPG/RANKL (osteoprotegerin/receptor activator of NF-kappa B ligand) ratio and serum interleukin-6 in male mice. J Endocrinol 171: 425-433, 2001.

35. Bord S, Ireland DC, Beavan SR and Compston JE: The effects of estrogen on osteoprotegerin, RANKL, and estrogen receptor expression in human osteoblasts. Bone 32: 136-141, 2003.

36. Zhai YK, Pan YL, Niu YB, Li CR, Wu XL, Fan WT, Lu TL, Mei QB and Xian CJ: The importance of the prenyl group in the activities of osthole in enhancing bone formation and inhibiting bone resorption in vitro. Int J Endocrinol 2014: 921954, 2014.

37. Takayanagi H, Kim S, Koga T, Nishina H, Isshiki M, Yoshida H, Saiura A, Isobe M, Yokochi T, Inoue J, et al: Induction and activation of the transcription factor NFATc-1 (NFAT2) integrate RANKL signaling in terminal differentiation of osteoclasts. Dev Cell 3: 889-901, 2002.

38. Crabtree GR and Olson EN: NFAT signaling: Choreographing the social lives of cells. Cell 109 (Suppl): S67-S79, 2002. 